\title{
STUDENTS' PERCEPTIONS OF ONLINE LEARNING IN CRITICAL AND CREATIVE READING COURSES UMMY SOLOK
}

\author{
Mega Putri \\ Universitas Mahaputra Muhammad Yamin, Solok, Indonesia \\ megamocaputri@gmail.com
}

\begin{abstract}
This research was motivated by the Covid-19 pandemic which changed the order of life, including in the world of education. Online learning is a solution so that learning continues even with all its advantages and disadvantages. However, it needs adjustments both in terms of lecturers and students in its implementation. In the learning process, the main things that must exist include: teaching and learning process, competence of lecturers and facilities and infrastructure. The purpose of this study was to analyze students perceptions of online learning in the Critical and Creative Reading course at UMMY Solok. This type of research is survey research. The data collection technique is in the form of a questionnaire, the questionnaire used is a closed questionnaire type in the form of a rating scale, namely a questionnaire that has available answers, then analyzed using descriptive statistics. The results of this study explain that the learning process is categorized as good, lecturer competence is in good category, and facilities and infrastructure are in sufficient category. From the results, it can be concluded that in online learning the teaching and learning process has been going well and the competence of lecturers in providing learning is also good even though the facilities and infrastructure are still lacking. Improvements are needed not only in terms of students and lecturers but also the campus.
\end{abstract}

Keywords : Perception, Online Learning, UMMY Solok

\section{PENDAHULUAN}

Pembelajaran daring (dalam jaringan) merupakan kegiatan yang sangat akrab bagi masyarakat dunia satu tahun belakang ini. Tidak terkecuali masyarakat kampus yang harus menerapkan pembelajaran yang berbasis teknologi ini. Segala sarana prasana harus dipenuhi agar tujuan pembelajaran tercapai. Hal ini terjadi karena pandemi yang melanda dunia yaitu Covid-19.

Covid-19 membuat segala sesuatu berubah dengan menerapkan normal baru dalam setiap kegiatan sosial termasuk dalam pendidikan. Pendidik diharapkan mampu memahami dan mengaplikasikan teknologi yang ada 
untuk pembelajaran daring. Jenis aplikasi yang dapat digunakan dalam pembelajaran dari seperti Whatsapp (WA), google classroom (GC), zoom meetting. Semua aplikasi tersebut dapat dikombinasikan dalam pelaksanaan pembelajaran daring.

Pada pembelajaran menggunakan WA untuk dosen dapat mengirim bahan ajar dan mendiskusikan dengan mahasiswa tetapi tidak dapat bertemu wajah dengan mahasiswa, sama dengan menggunakan GC. Satu lagi aplikasi yang biasa digunakan dalam pembelajaran adalah zoom meeting, pada Zoom ini mahasiswa dapat bertemu wajah secara virtual, dosen dan mahasiswa bisa langsung berdiskusi.

Dalam perkuliahan daring mahasiswa dan dosen dapat melakukan kegiatan pembelajaran dari tempat yang berbeda. Ini merupakan solusi yang dapat digunakan agar pembelajaran tetap berjalan walaupun dalam situasi dan kondisi pandemi saat ini.

Namun, pembelajaran daring ini memiliki beberapa kendala seperti jaringan internet yang kadang tidak stabil sehingga membuat pembelajaran tidak efektif, lokasi atau tempat belajar yang dilakukan di rumah masing-masing sehingga membuat mahasiswa kurang konsentrasi dalam mengikuti perkuliahan. Selain itu, mahasiswa dan dosen dibebankan biaya tambahan untuk membeli kuota untuk penggunaan internet.

Sebagai pembelajaran yang belum biasa bagi siswa tentunya butuh penyesuaian dalam melaksanakan pemebelajaran daring ini, baik bagi dosen maupun mahasiswa. Secara umum ada tiga pokok dalam proses pembelajaran itu antara lain: proses belajar mengajar, kompetensi dosen, dan sarana dan prasana. Ketiga hal tersebut harus terpenuhi agar tujuan pembelajaran dapat tercapai.

\section{KAJIAN PUSTAKA}

Persepsi adalah gambaran, pandangan atau anggapan seseorang tentang suatu objek atau suatu hal. Persepsi juga diartikan sebagai proses diterimanya rangsang (objek, kualitas, hubungan antar gejala maupun peristiwa) sampai rangsang itu disadari dan dimengerti.reaksi seseorang terhadap suatu objek dapat diwujudkan dalam bentuk sikap atau tingkah laku seseorang tentang apa yang dipersepsikan. (Irwanto, 1991:71).

Miftah (2003:154) menyatakan bahwa faktor-faktor yang mempengaruhi persepsi seseorang adalah sebagai berikut:

a. faktor internal meliputi perasaan, sikap dan kepribadian individu, prasangka, keinginan atau harapan, perhatian, proses belajar, keadaan fisik, gangguan kejiwaan, nilai dan kebutuhan juga minat dan motivasi.

b. Faktor eksternal meliputi latar belakang keluarga, informasi yang diperoleh, pengetahuan dan kebutuhan sekitar dan intensitas.

Pembelajaran adalah suatu proses yang terdiri dari dua aspek yaitu belajar tertuju pada apa yang dilakukan siswa, mengajar berorientasi pada apa yang harus dilakukan oleh guru sebagai pemberi 
pelajaran.

Dalam

proses

pembelajaran terjadi interaksi positif antara guru dan siswa dengan segala potensi dan sumber yang ada.

Usman (dalam K Gilang, 2020: 12) berpendapat bahwa pembelajaran adalah inti dari proses pendidikan secara keseluruhan dengan guru sebagai pemegang peranan utama. Proses pembelajaran mengandung serangkaian perbuatan guru dan siswa atas dasar hubungan timbal balik yang berlangsung secara edukatif untuk mencapai tujuan pembelajaran.

Tung dalam Mustofa (2019: 154) menyebutkan karakteristik dalam pembelajaran daring antara lain:

1) Materi ajar disajikan dalam bentuk teks, grafik dan berbagai elemen multimedia,

2) Komunikasi dilakukan secara serentak dan tak serentak seperti video conferencing, chats rooms, atau discussion forums,

3) Digunakan untuk belajar pada waktu dan tempat maya,

4) Dapat digunakan berbagai elemen belajar berbasis CD-ROM untuk meningkatkan komunikasi belajar,

5) Materi ajar relatif mudah diperbaharui,

6) Meningkatkan interaksi antara mahasiswa dan fasilitator,

7) Memungkinkan bentuk komunikasi belajar formal dan informal,

8) Dapat menggunakan ragam sumber belajar yang luas di internet

Selain itu Rusma dalam Herayanti, Fuadunnazmi, \& Habibi (2017:211) mengatakan bahwa karaktersitik dalam pembelajaran e-learning antara lain:
1) Interactivity (interaktivitas),

2) Independency (kemandirian),

3) Accessibility (aksesibilitas),

4) Enrichment (pengayaan).

\section{METODE PENELITIAN}

Penelitian ini merupakan penelitian deskriptif yang termasuk pada jenis penelitian survai. Penelitian deskriptif adalah penelitian yang diarahkan untuk memberikan gejala-gejala, fakta-fakta atau kejadian-kejadian secara sistematis dan akurat, mengenai sifat-sifat populasi atau daerah tertentu. Salah satu jenis penelitian deskriptif adalah penelitian survei yang merupakan penelitian dengan mengumpulkan informasi dari satu sampel dengan menanyakan melalui angket atau interview supaya nantinya menggambarkan berbagai aspek dari populasi (Riyanto, 2010: 23).

Populasi dalam penelitian ini yang adalah semua mahasiswa pendidikan Bahasa Indonesia semester IV tahun ajaran 2020/2021 yang berjumlah 15 orang di Program Studi Pendidikan Bahasa Indonesia FKIP UMMY Solok yang telah mengikuti proses Membaca Kritis dan Kreatif. Sedangkan sampel adalah mahasiswa pendidikan Bahasa Indonesia semester IV tahun ajaran 2020/2021 yang berjumlah 15 orang di Program Studi Pendidikan Bahasa Indonesia FKIP UMMY Solok. Teknik pengambilan sampel menggunakan total sampling.

\section{HASIL DAN PEMBAHASAN}

Data persepsi mahasiswa didapatkan melalui angket yang diisi oleh 14 orang mahasiswa yang 
Vol. 3 No. 2

December 2021

e- ISSN 2685 - 0559

p- ISSN $2684-673 X$

mengikuti perkuliahan Membaca Kritis dan Kreatif. Setelah dilakukan analisis data dengan mencari mean atau rerata dari setiap pernyataan yang ada pada angket maka didapatkan hasil seperti yang tertera pada tabel berikut ini.
NO. PERNYATAAN

Rata-Rata

1. Materi yang dipelajari sesuai dengan RPS

2. Jadwal perkuliahan sering berganti

3,1

3. Saya senang dengan pembelajaran daring karena waktunya bisa diatur ulang

4. Pembelajaran memberikan kemudahan bagi saya berinteraksi dengan dosen

5. Tugas yang diberikan dosen sangat sulit dikumpulkan saat perkuliahan daring

6. Dalam kuliah daring kurang terasa kedekatan dengan dosen

7. Kuliah daring mempermudah saya belajar dimana saja

8. Dalam diskusi saat pembelajaran daring media untuk mencari jawaban sangat banyak

9. Menyelesaikan masalah sesama mahasiswa lebih mudah dengan pembelajaran daring

10 Miskomunikasi antara dosen dengan mahasiswa lebih sering terjadi dalam pembelajaran daring

11. Jaringan tidak mendukung saat perkuliahan berlangsung

12. Jaringan sering hilang saat mengunduh materi

3,8

4,5

2,8

2,6

4,4

4,7

3,2

2,6

2,6

2,5

4,3

2,3

14. Saya sulit mengirimkan tugas karena memiliki tugas lebih karena harus mengirim tugas yang telah ditulis tersebut

15. Tugas yang diberikan membantu saya memahami materi yang diberikan

16. Dosen sering tidak konsentrasi dalam perkuliahan

3,1

17. Dosen menjelaskan setiap materi perkulihan dan mudah dipahami

18. Media perkuliahan daring menjadikan saya untuk lebih giat dalam mempraktekkan membaca pemahaman

19. Pembelajaran daring membuat saya tidak bersemangat karena situasi dirumah tidak sama dengan pembelajaran tatap muka

20. Saya lebih suka pembelajaran tatap muka

21. Saya tidak paham dengan pembelajaran daring

22. Saya tidak bisa mencari buku untuk pembelajaran saat 


\section{daring}

23. Jaringan di tempat saya tidak bagus sehingga menyulitkan 2 saya dalam perkuliahan

24. Saat hujan jaringan sering terganggu sehingga saya tidak 1,6 bisa memahami secara baik materi yang ada

Penelitian tentang persepsi mahasiswa terhadap pembelajaran daring pada matakuliah Membaca Kritis dan Kreatif UMMY Solok terdiri atas 3 aspek pengukuran yaitu Proses Belajar Mengajar, Kompetensi Dosen, dan Sarana dan Prasarana.

\subsection{Proses Belajar Mengajar}

Proses dalam kegiatan pembelajaran sangat penting dalam sebuah pendidikan. Proses salah satu faktor penentu keberhasilan dalam pembelajaran. Pada aspek ini terdapat uraian dan jabaran yang tertuang dalam indikator.

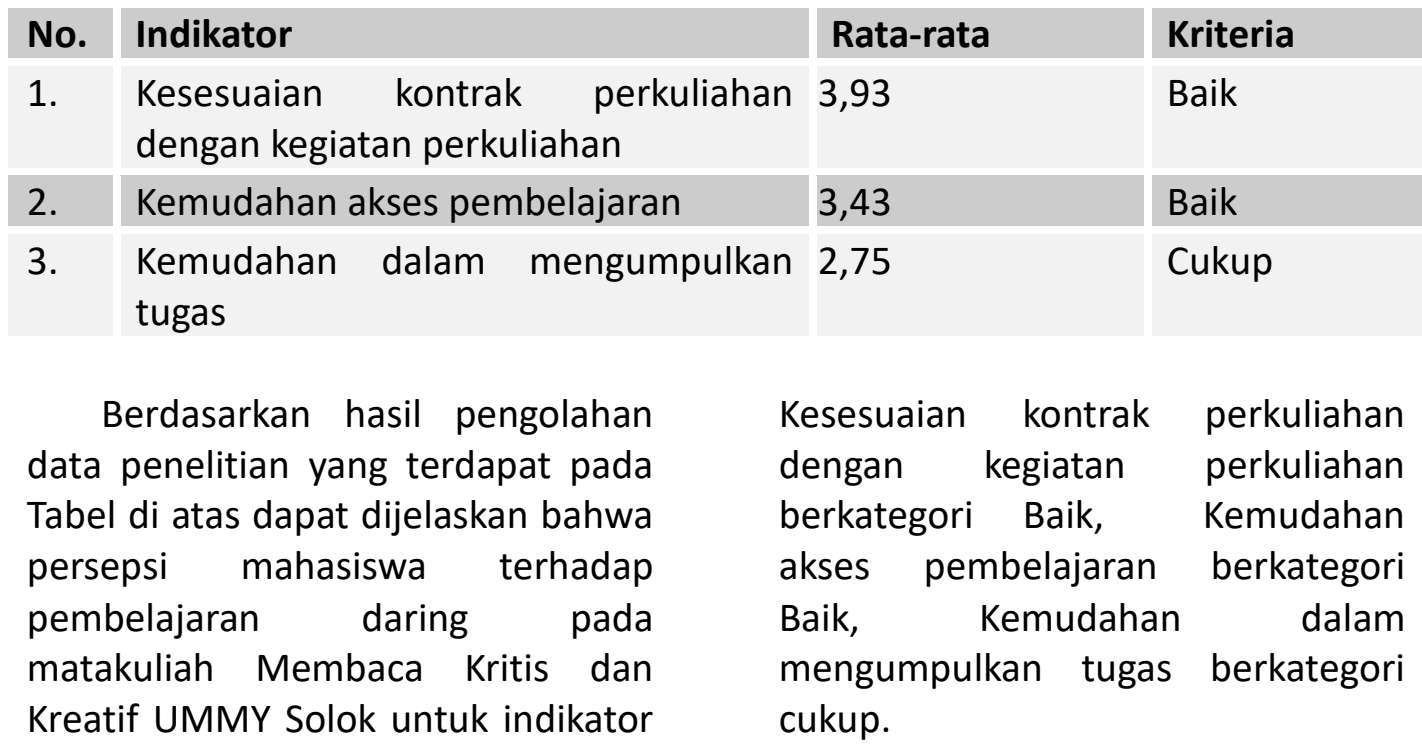

\subsection{Kompetensi Dosen}

\begin{tabular}{|l|l|l|l|}
\hline No. & Indikator & Rata-rata & Kriteria \\
\hline 1. & $\begin{array}{l}\text { Kecakapan dosen } \\
\text { menyampaikan materi }\end{array}$ & dalam 3,47 & Baik \\
\hline 2. & $\begin{array}{l}\text { Pemahaman terhadap materi } \\
\text { perkuliahan oleh siswa }\end{array}$ & B,52 & Baik \\
\hline
\end{tabular}

Berdasarkan hasil pengolahan data penelitian yang terdapat pada Tabel di atas dapat dijelaskan bahwa persepsi mahasiswa terhadap pembelajaran daring pada matakuliah Membaca Kritis dan Kreatif UMMY Solok untuk indikator Kecakapan dosen dalam menyampaikan materi berkategori Baik, Pemahaman terhadap materi perkuliahan oleh siswa berkategori Baik. 
4.3. Sarana dan Prasarana
No. Indikator
Rata-rata
Kriteria
1. Ketersediaan jaringan yang memadai
2,18
Cukup
2. Ketersediaan Buku referensi/Buku ajar 3,05
Baik

Berdasarkan hasil pengolahan data penelitian yang terdapat pada Tabel di atas dapat dijelaskan bahwa persepsi mahasiswa terhadap pembelajaran daring pada matakuliah Membaca Kritis dan Kreatif UMMY Solok untuk indikator Ketersediaan jaringan yang memadai berkategori Cukup dan Ketersediaan Buku referensi/buku ajar berkategori Baik.

\section{KESIMPULAN}

Berdasarkan hasil penelitian dapat disimpulkan bahwa persepsi mahasiswa terhadap pembelajaran daring pada matakuliah Membaca Kritis dan Kreatif UMMY Solok meliputi:

1. Kesesuaian kontrak perkuliahan dengan kegiatan perkuliahan berkategori Baik,

2. Kemudahan akses pembelajaran berkategori Baik,

3. Kemudahan dalam mengumpulkan tugas berkategori cukup,

4. Kecakapan dosen dalam menyampaikan materi berkategori Baik,

5. Pemahaman terhadap materi perkuliahan oleh siswa berkategori Baik,

6. Ketersediaan jaringan yang memadai berkategori Cukup,

7. Ketersediaan Buku referensi/buku ajar berkategori Baik.

\section{REFERENSI}

Maulana, \& Hamidi, "Persepsi mahasiswa terhadap pembelajaran daring pada mata kuliah praktik di Pendidikan Vokasi" Equilibrium: Jurnal Pendidikan, Vol. 8 No. 2 (2020): 224-231.

DOI:

10.26618/equilibrium.v8i2.3443

Saragih, Oerdekoria. Persepsi Mahasiswa terhadap

Pembelajaran Daring Selama Pandemi Covid-19. Jurnal Penelitian Pendidikan \& Pembelajaran, Volume 7 (3), 2020178.

Asrori, Mohammad. (2009). Psikologi Pembelajaran. Bandung. CV Wacana Prima.

Gilang R. (2020). Pelaksanaan Pembelajaran daring di Era Covid-19. Jawa Tengah: Penerbit Lutfi Gilang

Miftah, Toha. (2003). Perilaku Organisasi Konsep Dasar dan Aplikasinya. Jakarta: Grafindo Persada.

Kučírková, "Comparison of Study Results of Business English Students in e-learning and Face-to-face courses" Journal on Efficiency and Responsibility in Education and Science, Vol. 5 No.3 (2012): 173-184. https://doi.org/10.7160/eriesj.2 012.050306. 